\title{
"It was the brain tumour that done it!" Szasz and Wittgenstein on the importance of distinguishing disease from behaviour and implications for the nature of mental disorder
}

\begin{abstract}
The current paper looks at the distinction between bodily conditions, such as diseases, which may affect behaviour, and situations that comprise self-directed behaviour. This distinction was emphasised by the late Thomas Szasz, who recognised that regarding a situation as a disease or illness has important consequences that flow from the association of these concepts with the body. Wittgenstein's critique of the concept of mind helps to clarify and support Szasz' intuitions. Both Szasz and Wittgenstein suggest that we misunderstand the nature of 'mind', and that mental states and events are not independent entities that can be discovered and described by natural science, but activities of living human beings that are manifested in, and recognised through, forms of public behaviour. Mental disorders, which are also manifested in behaviour, cannot, therefore, be aligned with biological conditions, unless there is evidence of an underlying disease. Attempts to expand the concepts of illness and disease by separating them from their bodily context, in order to accommodate mental disorders within a medical framework, only denude the terms of any distinctive meaning. Wittgenstein, like Szasz, suggests that what we characterise as mental illness, therefore, refers not to an illness or disease, but to patterns of unusual but still essentially self-directed behaviour. These patterns can be understood as aspects of character, although they have a complex relationship to agency. The implications of this analysis for the justification of psychiatric coercion and the treatment of common psychological complaints are explored.
\end{abstract}


Keywords: disease concept; mental disorder concept; Szasz; Wittgenstein philosophy of mind; medical model of mental disorder 


\section{"It was the brain tumour that done it!" Szasz and Wittgenstein on the importance of distinguishing disease from behaviour and implications for the nature of mental disorder}

In Patricia Churchland's 2006 essay on free will she cites the case of a middle aged man who, without any prior history of misbehaviour, suddenly became obsessed with child pornography and started to molest his 8 year old step daughter. He was subsequently discovered to have a brain tumour affecting the frontal lobes, and when it is successfully treated his aberrant behaviour stopped (Churchland, 2006).

Thomas Szasz is famous for his denunciation of the concept of mental illness, and his critique is partly responsible for instigating an enduring philosophical discourse about the nature of mental disorder. Szasz' key insight was the recognition that we find it important to distinguish between situations that are characterised by 'ordinary' human behaviour and those that arise from a bodily condition or event, such as a disease. Although Churchland put it to different ends (to question the nature of agency per se), from Szasz' perspective, her example demonstrates the importance of this distinction because it shows how we understand and respond to paedophilic behaviour brought on by a brain tumour quite differently from an ordinary criminal case of paedophilia.

For Szasz, the concept of a disease is essentially and irreducibly one that applies to the physical body. It can only be applied to 'behaviour' when a bodily condition can be understood to be directly driving or causing the behaviour in question, which then ceases to have the characteristics of ordinary behaviour and can sensibly be described as 'symptoms' of a disease, or the result of some other bodily alteration such as that induced by psychoactive 
drugs . According to Szasz, human behaviour, as opposed to neurological symptoms, cannot constitute a disease, because behaviour is not a biological entity, and it cannot be adequately explained by the presence of a biological process (Szasz, 1989, 2000). Since what is referred to as 'mental illness' consists of problematic behaviour that cannot be attributed to neurological or pharmacological causes, it cannot legitimately be thought of as a disease, or a related term such as an 'illness.'

Although prominent psychiatrists claim that some or all mental disorders are, in fact, diseases of the body, specifically the brain (Insel \& Cuthbert, 2015), few philosophers want to equate mental disorder with brain disease. Most, nevertheless, want to incorporate it into a medical framework. With some exceptions (e.g. Fulford, 1989), recent philosophical debates have avoided the question of the distinction between bodily conditions and situations characterised by unusual and problematic behaviour, discussing instead whether mental disorders are natural, social, practical or eclectic 'kinds' (Hartner \& Theurer, 2018; Kendler, Zachar, \& Craver, 2011; Zachar, 2002) and whether they should be characterised as valuefree or value-laden (Boorse, 1976; Fulford, 1989; Sedgwick, 1982; Wakefield, 1992).. A common approach is to incorporate mental disorder into the territory of disease by suggesting some analogy between the biological and psychological realms, thereby implicitly or explicitly stretching the concept of disease beyond the body (Boorse, 1976; Fulford, 1989; Sedgwick, 1982; Wakefield, 1992). This contrasts with philosophers of science who are not concerned with mental disorder, who often simply assume that concepts like disease and illness refer to bodily conditions. French philosopher of biology, Georges Canguilhem, for example, states that "one can speak with reason of "Greek Medicine" only from the Hippocratic period onward-that is to say from the moment when diseases came to be treated as bodily disorders' (Canguilhem, 2012) (p. 35). 
Yet, philosophers who take an 'anti-positivist' position have long suggested that it is important to distinguish how we understand the material world, which includes autonomous biological processes like diseases, from our understanding of human behaviour. Ludwig Wittgenstein provides an example of this approach, which is rooted in his powerful critique of conventional ideas about the nature of 'mind'.

Szasz has rarely been placed in a wider philosophical context, yet his view of 'mind' and its relationship to behaviour is remarkably similar to that of Wittgenstein. In this paper I use Wittgenstein's philosophical analysis to support and clarify Szasz' position on the importance of distinguishing between disease and behaviour, and the implications this has for how we conceive of, and respond to, mental disorder. Like Szasz, I suggest that the issue has been neglected because of the strategic benefits of obscuring the distinction and the challenging implications that arise from accepting it.

\section{The nature of 'mind' in Wittgenstein and Szasz}

Szasz and Wittgenstein express a common view that what are referred to as 'mental states' or just 'mind' are not properly thought of as 'internal' phenomena that can be analysed using the methods of natural science. Thoughts and emotions, as we normally understand them, cannot sensibly be described as brain events nor as independent psychological events or processes. They are, instead, properties of living human beings that are expressed, and made sense of, within particular material and social circumstances and in the context of individual biographies.

Wittgenstein's later philosophy suggests that, under the growing influence of science, we have mistakenly come to think of mental attributes as 'things' that have their own properties, and can be known independently from the sort of organisms that manifest them. 
We see the mind as a separate entity that can be regarded as causing human actions, just as a mechanical process might cause a material body to move, or a nervous reflex might cause one's knee to jerk. We have come to understand ourselves as beings that are not co-extant with, but that have minds, and by doing this we introduce an illusory schism between ourselves and our minds.

This position, which arises with Descartes and Locke, has become deeply embedded in 'the grammar of our languages', according to the Wittgenstinian scholar, Peter Hacker, and fundamentally distorts our understanding of the 'mental' ( Hacker, 1997) (P. 14). In contrast, Wittgenstein and Szasz argue that what we think of as mental events or processes, that is thoughts, emotions, attitudes and sensations, are not essentially private and internal, but are unavoidably manifested in public behaviour. Indeed, behaviour is constitutive of our understanding of what mental states and processes consist of, and particular forms of behaviour constitute the criteria for our attribution of a mental phenomenon to an individual in a particular situation. We express our beliefs, feelings and experience through words, gestures and actions, all of which derive their meaning through the way they are used in a public context.

The 'inner' world of thoughts and feelings is thus integrally entwined with 'outer' behaviour; and behaviour is 'infused' with the 'inner' ( Hacker, 1997) (p.42). One does not cause the other, they are aspects of one and the same thing! As Wittgenstein commented, 'the human body is the best picture of the human soul' ( Hacker, 1997; Wittgenstein, 1953), cited in Hacker, 1997, p. 44).

In Philosophical Investigations Wittgenstein famously gives the example of pain and shows that we learn how to use the term 'pain' to describe our own experiences through learning how the term is applied to situations in which other people are said to be in pain. 
The first person and third person use are indissolubly linked, and the first person use to describe a personal experience is only logically possible given mastery of the third person use, which is based on behavioural grounds or criteria (Wittgenstein, 1953).

Hacker describes how emotions and moods are also understood through particular public expressions that form the criteria for ascribing an emotional state to an individual ( $\mathrm{P}$. M. Hacker, 2004). Some emotions are demonstrated by an immediate reaction, like a smile, or expression of surprise, and some, like sadness, grief or anxiety, by longer lasting patterns of behaviour. Implicit in emotion language is the idea that the feeling is typically a reaction to someone or something. Love, hate and anger often have as their object another living being. Surprise and delight are usually immediate reactions to proximate events. Sadness, fear, guilt, shame and happiness are less immediate reactions, but also normally understood as responses to something that has happened, is happening or might happen to someone. Part of the context of emotion language is the object or events at which the emotion is directed. In other words, unlike physical sensations or physiological states, such as hunger or pain, emotions and moods, like thoughts and behaviour, are usually meaningful.

Szasz, too, stresses the behavioural aspect of mental states or feelings. Like other writers, Szasz points out that the noun 'mind' is only a few centuries old, and Szasz suggests that it would be better understood in the sense of the old verb 'to mind'. 'Minding' can be understood as what humans being do and how they respond to the world around them. Incidentally, Hacker also points out how current uses of the noun 'mind' can be replaced by verbs, concluding that 'mind' is 'an oblique way of speaking about human faculties and their exercise' (Hacker, 2010) (p. 250). For Szasz, when we use the language of intention, belief or emotion we indicate that a person cares about, or has a position on, something; that they 'mind;' and as he points out 'how and what we mind is who we are' (Szasz, 1996) (p. 17). Szasz, like Wittgenstein, suggests, therefore, that mental attributes are not aspects of some 
mysterious, aethereal object called the mind, nor of a material object such as the brain. They are attributes of human beings whose behaviour is in constant interaction with the social and material conditions of their existence. The 'mind' in this view refers to the 'sum total of what a person does and says' (Szasz, 1996) (p. 19).

Szasz stresses how 'minding' is a particularly human characteristic that is an expression of our rational nature. Being 'creatures that mind' entails that we evaluate situations and can make reasoned decisions about what we do. On this view, our behaviour is a manifestation of our human agency, and the concomitant of this is that we can be regarded as responsible for our actions. For Szasz, therefore, the 'concepts of right and wrong, responsibility and mind' (Szasz, 1996, p. 43) are closely interdependent.

Like Wittgenstein, Szasz suggests that we have been enticed into regarding human behaviour and mental orientations as a substance, a thing we call 'the mind'; 'we misunderstand "minding" as using our "mind" (Szasz, 1996) (p. 17). This separation of 'mind' from the whole living, acting human being enables us to downplay the moral aspects of behaviour. When actions are attributed to the mind rather than the person, responsibility can be displaced. When the mind is further equated with the brain, the issue of responsibility is dissolved altogether.

For Szasz as for Wittgenstein, therefore, our language of mental states and emotions signifies attributes of whole living persons who are actively engaged in the social and material world. Our thoughts and emotions are not just, or primarily, private events - whether these are conceived as taking place in the brain or the 'mind'. We recognise and identify these situations through the behaviours and reactions that people express publically, and the context in which these occur. 
We can apply this view to the situations we refer to as mental disorder, such as 'depression.' There are various patterns of behaviour we might associate with this emotion as broadly conceived. Someone might take to bed and cease to go about their everyday life. They might cry easily and display obvious signs of distress. Someone might become preoccupied with a negative and pessimistic view of the world. Someone may visit a doctor or other professional to say that they are not feeling 'right' and are struggling to cope with their responsibilities, or they may simply say that they are not happy to those around them. When we speak of someone as becoming depressed, we imply a change in their behaviour. The 'depressed behaviour' is new; previously the individual was acting 'normally'. The important point is that the sorts of behaviours we associate with depression are not the mere external manifestations of some 'inner' state that is what depression really is, whether that is thought of as a brain condition or a private mental state. When we refer to someone as 'depressed', even when we do this within the framework of diagnostic systems like the Diagnostic and Statistical Manual (the DSM), we are not identifying the real nature of their nervous system or mental make-up. We are talking about the sorts of behaviours they are displaying, and our normal understanding of how these reflect their thoughts, feelings and intentions.

\section{Understanding the mental}

Wittgenstein's analysis of the nature of 'mind' is consistent with anti-positivist currents in philosophy which were emerging from the $19^{\text {th }}$ century. Those who take an anti-positivist position argue, in opposition to positivism ${ }^{\mathrm{i}}$, that the concepts and methods we use to investigate the natural world in a scientific manner are fundamentally different from the ways in which it is appropriate and meaningful to understand human behaviour, and the mental 
attributes that it manifests. Scientific methods and theories are premised on the predictability of the physical environment, which in turn derives from the fact that non-living things do not have volitional agency. Unlike inanimate matter, living organisms behave in 'purposeful' ways, in order to maximise their chances of survival and reproduction ( Hacker, 2010). Higher animal life has the capacity to respond flexibly to the environment through selfdirected action. Human beings, moreover, have the capacity for 'reason,' that is, they can reflect on and weigh up the options available to them. Unlike the subject matter of the physical sciences, therefore, people have motives, interests and purposes, they make choices and do things for reasons. Although human actions are, of course, influenced and constrained by various factors including human biology and the current and past circumstances of each individual's life, they are not determined. They cannot simply be understood as the inevitable product of a given set of conditions. It is argued, therefore, that understanding human behaviour is logically different from the way we understand the material world (Winch, 2008). In particular, knowledge about human activity does not result in universally applicable laws or principles, and it cannot be 'objective' in the way that our knowledge of the material world strives to be because the researcher can never stand outside the world she is researching. There is no neutral point of view. Wittgenstein's particular contribution to this debate is his demonstration that 'the mind,' or the mental, since it is indissolubly linked with human behaviour, cannot be grouped in with the material world and investigated using the approach of natural science. Our psychological attributes are human affairs, not 'natural' ones.

This analysis shows how the arguments of the 'naturalists', such as Boorse (Boorse, 1976) and Wakefield (Wakefield, 1992), who regard mental functions as analogous to biological functions, are misguided. The idea that dysfunctional psychological processes that can be understood in the same way as dysfunctional biological processes is to misunderstand 
the nature of mental states and events. It fails to appreciate the link between mental attributes and the behaviour in which they are manifested, and the way that this behaviour derives its meaning from the social world in which it is embedded.

These philosophers do, however, identify the important point that we want to use the term 'disease' to describe a characteristic situation that is associated with the material world and is amenable to scientific description and investigation. In this sense they accept Szasz' position that there is a distinction between disease and situations characterised by problematic behaviour. However, their aim is to incorporate mental disorders into the concept of disease in order to establish them firmly within the realm of medicine and science, and to refute the Szaszian claim that they belong in the world of behaviour.

\section{Distinguishing disease and behaviour}

In contrast, and in line with the anti-positivist position, Szasz understands that mental processes, including those that occur in the context of what we call a mental disorder, are inextricably linked with behaviour, and that behaviour, as it normally occurs, is categorically different from a biological state such as a disease. As part of the material world, bodily processes are biologically programmed in ways over which human beings have limited control. Our bodies grow and develop in characteristics ways following general laws of human biology and development. Similarly, cancer cells multiply and disseminate in a predictable fashion that is a consequence of the inherent nature of cells in general and cancer cells in particular. We can influence our bodies by acting on them. We can develop muscle mass by exercising, increase or decrease our weight through modifying our diet, for example. We can sometimes modify a disease process, too, by acting on our bodies through physical means like taking drugs, going on a diet or making ourselves relax to reduce pain or 
wheezing. Nevertheless, just as we are subject to the inexorable logic of biological aging, we cannot rid ourselves of cancer just because we wish to (or so most people believe and science indicates). We cannot modify arthritis by an act of will alone. Biological processes are governed by predictable regularities which, like chemical reactions, have nothing to do with the desires and purposes of individual human beings. Thus, we can apply a scientific framework to biological matter, one that is based on identifying and characterising universal laws based on causal relationships between entities and events..

We have already seen that a disease of the brain or another part of the body can cause certain behaviours or activity, such that it makes sense to say that the result is attributable to the disease, rather than the individual's agency. An epileptic fit, for example, is the result of anomalous electrical activity in the brain. It does not count as 'behaviour' as we ordinarily know it. Similarly, the brain tumour in Churchland's example directly influenced the behaviour of the sufferer, producing actions that were 'out of character.' Brain diseases like dementia and advanced multiple sclerosis (MS) also commonly produce more or less subtle changes in a person's behaviour. The bodily conditions that give rise to these situations are biological entities or processes that are part of the natural world. Therefore it is appropriate to describe them in terms of biological science, and to investigate their nature and origins using scientific methods, just as we can look for the bodily origins and mechanisms of pain. We can meaningfully speak in terms of the biological processes 'causing' characteristic 'behaviours' (which we then refer to as symptoms), in the sense that the latter are a predictable consequence of the former. Identifying the specific abnormalities that constitute the disease can lead to the development of medical 'treatment,' which will be designed, ideally, to act on the abnormal anatomical, biochemical or physiological pathways at some level.

For Szasz, only 'behaviour' that is directly driven by a biological process in this way can be deemed to be an illness or disease, or the symptoms of such. Szasz illustrates the 
importance of the distinction between bodily events and ordinary behaviour by highlighting how we distinguish an intentional action like a wink, which has meaning and purpose, from an involuntary muscle spasm such as a blink or twitch of the eye, even though the actual movement may be the same in both cases (Szasz, 1996, p. 24). We can also think of the difference between a deliberate kick and a muscle spasm. Behaviour that is not the direct result of a biological process, is, by definition, the expression of an autonomous human being, a manifestation of human agency. This not to suggest that behaviour does not involve physiological or neurochemical alterations, but ordinary behaviour is not properly thought of as a casual consequence of such alterations (unless you are a eliminativist or neurodeterminist, like Churchland, who wants to re-describe all human activity in terms of neural events, a position that has been rebutted by numerous thinkersii).

Churchland's example of the brain tumour illustrates how it is evident that in real life we do, as Szasz suggests, find it important to distinguish situations that arise as a consequence of a bodily state or event, and those that consist of ordinary human behaviour, that is activity initiated by an autonomous, self-directing individual. The distinction between epileptic fits and contrived fits provides another example. We think of someone as having the disease of epilepsy when we have reason to believe that the 'fits' they show are due to abnormal electrical impulses in the brain. But we know that sometimes people imitate epileptic fits for various reasons. In medicine, these situations are distinguished from actual epilepsy by referring to them as 'pseudo seizures' or 'functional' seizures.

We treat people who imitate fits, whether they do so consciously or unconsciously, differently from people whose fits originate from abnormal brain currents. Working in a drug detoxification unit making the distinction is an everyday challenge. People who have been using large amounts of alcohol or benzodiazepine drugs are liable to have epileptic fits during detoxification, which can be life-threatening and need immediate treatment with anti- 
epileptic agents. People with a history of addiction may also fake fits, however, in order to obtain these substances. If you give people who fake fits anti-epileptic drugs, you not only expose them to unnecessary harm, you also undermine the principles of the recovery programme for everyone involved.

Such situations illustrate the problem with views that try to uncouple disease or illness concepts from the body. Thinkers such as Bill Fulford and Peter Sedgwick, for example, suggest that what is fundamental to these concepts is that they signify situations that are unwanted, because they cause pain or discomfort, or because they prevent us doing what we want to be doing (referred to as 'action failure' by Fulford) (Fulford, 1989; Sedgwick, 1982). In other words, they are evaluative terms. Therefore, they argue, unwanted mental states or disorders can also qualify as disease or illness. As Wittgenstein illustrates, however, we cannot hive off the psychological from the realm of human social behaviour, and eliding mental and physical illness on the basis that both sorts of conditions cause suffering, discomfort or functional failure implies there is no value in distinguishing between an unwanted condition of the body, and other unwanted situations that involve various sorts of human behaviour. Yet this is clearly not true. Cancer and burglary are both negatively valued situations but that does not make them the same sort of thing!

Szasz did not deny, as is sometimes implied, that the concepts of disease and illness are evaluative concepts. He did not view a biological deviation as sufficient to define something as a disease in the absence of undesired consequences. A biological notion of disease still incorporates value judgements about what sorts of bodily states or attributes are 'normal' or desirable. Szasz merely observed that wanted or unwanted, bodily conditions can be described in terms of biology: 'although the desirability of physical health, as such, is an ethical norm, what health is can be stated in anatomical and physiological terms' (Szasz, 1989) (p. 14). If you loosen the association between the concepts of 'illness' and 'disease' 
and the body, you empty them of their distinctive meaning. They are no longer able to pick out a particular category of unwanted situations and they become synonymous with generic terms like 'problem' or 'difficulty'. We can no longer distinguish between the man with the brain tumour and the ordinary sex offender in terms of our moral evaluation or our practical response. Divorced from the body, 'disease' and 'illness' cease to have any discriminative power. They become meaningless.

\section{Mental disorder as brain disease}

Several leading psychiatrists agree with Szasz in the sense that they maintain that 'real' psychiatric conditions, as opposed to inappropriately medicalised aspects of ordinary life, are 'as yet to be discovered' brain diseases (Craddock et al., 2008). Although this position is logically consistent with the critique expressed above, it seems unlikely that it will ever account for most instances of what we currently refer to as mental disorder. It is sometimes claimed, for example, that mental disorders like schizophrenia or depression have, in fact, already been demonstrated to be brain diseases (Insel \& Cuthbert, 2015). However, the evidence is far from conclusive. The most consistent finding in schizophrenia is its association with reduced brain volume, but the confounding effects of intelligence have never been properly addressed, and recent research confirms that the association is, at least in part, a consequence of antipsychotic drug treatment (see Moncrieff \& Middleton, 2015 for a review of this literature). The idea that schizophrenia or psychosis is a consequence of abnormal dopamine levels is also not consistently supported and there is much contradictory evidence (Kendler \& Schaffner, 2011; Moncrieff, 2009). Similarly, the widely promoted theory that depression is a consequence of abnormal serotonin levels or activity has also never been convincingly demonstrated (Healy, 2015). Moreover, as Szasz pointed out many 
times, if we did discover that a particular disorder, or some cases of it, were caused by a specific neurological abnormality we would reconceptualise the situation. We would redesignate the problem either as a fully-fledged neurological condition that then comes within the domain of neurology, as occurred with neuro-syphilis, or we would, at least, distinguish it from 'run of the mill' mental disorders by referring to it as an 'organic,' or, in more recent terminology as a 'neuropsychiatric' condition, like dementia.

Although it can be argued that strong evidence for a biological causation may yet become apparent for some situations currently identified as 'mental disorder', it seems right to assume that behaviour is autonomous, unless proven otherwise, just as it is generally agreed that capacity should be presumed unless or until there is good evidence to the contrary.

A popular view on the nature of mental disorders, sometimes referred to as the 'biopsychosocial' model, suggests that biological factors may have a partial role in the causation of mentally disordered behaviour and experiences. Yet, it is not clear what it would mean for a physical process to be partially causative of behaviour. In particular, it is not clear how biological causation is compatible with agency. If we understand a 'behaviour' as being the direct result of a biological process, this takes it out of the realm of agency - as in the case of a blink or an epileptic fit. Biological causation trumps other explanations of behaviour. As described above, this is not to deny that biology is involved in ordinary behaviour too. Our characters are the result of complex interactions between our biology and our individual interests and desires as they have co-evolved through the course of our lives. Moreover, biological events co-occur with all autonomous behaviour, thoughts and feelings. We are a long way from being able to match specific biological states with any particular behaviours or mental events or states that are not symptoms of an established brain disease, however. Even 
if we could, this is not the same as identifying a biological cause or instigator of that behaviour.

\section{Mental disorder as behaviour or character}

If it is not the result of a neurological or bodily disease, then, as Szasz claimed, the behaviour that we classify as mental disorder is just that, a form of behaviour. Wittgenstein also suggested this in a passage in Culture and Value that is cited by Szasz (Szasz, 1990; Wittgenstein, 1970). Wittgenstein starts by suggesting

“Madness doesn't have to be regarded as an illness. Why not a sudden- more or lesschange of character?" (Wittgenstein, 1970, p. 62).

Wittgenstein's contrast of illness and character is consistent with Szasz' distinction between conditions that originate in the body and those that are constituted by ordinary human behaviour, and the thoughts and emotions that are expressed therein. Since the way we behave reflects what is seen as our character, madness can be seen as an aspect of character, although sometimes one that, somewhat unusually, only emerges from time to time.

Wittgenstein goes on to illustrate the conceptual similarity between the symptoms of madness and more familiar feelings and behaviours:

"Everybody is (or most are) mistrustful, and perhaps more so towards their relations than towards others. Is there any reason for mistrust? Yes and no. Reasons can be given for it but they are not compelling. Why shouldn't somebody become much more distrustful of other people? Why not much more withdrawn? Or devoid of love? Don't people get like this even in the ordinary course of events? Where is the line to be drawn here between will and ability? 
Is it that I will not open my heart to anyone any longer, or that I cannot? If so much can lose its attraction, why not everything? If someone is wary even in ordinary life, why shouldn't he—and perhaps suddenly—become much more wary? And much more inaccessible?" (Wittgenstein, 1970) (p. 62).

The suggestion that rather than the eruption of a diseased brain, madness should be understood as a complicated, and possibly confused but self-directed reaction to the world is reminiscent of other attempts to explore the meaning of madness. The leading American psychiatrist of the mid-20 $2{ }^{\text {th }}$ century, Adolf Meyer, proposed that 'mental illness' consisted of people's attempts to manage circumstances they found to be challenging or uncomfortable. It was, he described, 'a genuine but faulty attempt to meet situations, an attempt worthy of being analysed' (Meyer, 1948) (p. 136). A behavioural 'symptom', such as social withdrawal, for example, can be understood as an attempt to resolve or avoid a personal dilemma, but one that soon becomes a problem in its own right. This is similar to R.D. Laing's views of psychosis as a retreat into an internal world that is motivated initially by the desire to avoid what is, for some, the intolerable anxiety of modern adulthood (Laing, 1965).

Some of the behaviours and utterances we associate with mental disorder are not straight-forwardly meaningful or what we would generally accept as rational, however. They do not have a purpose that is readily apparent to other people, and sometimes reasoning processes seem to be awry, or at least quite different from those of ordinary life. People with delusions, for example, can form beliefs on the basis of illogical and unlikely connections between events, and are usually not amenable to counter-arguments or evidence. They seem to have stepped outside the shared assumptions about the world that make normal social interactions possible. Indeed, ethnomethodologist Jeff Coulter, who was much influenced by Wittgenstein, argues that 'mental illness' is attributed when someone acts in a way that is not 
easily intelligible, and breaks the unwritten rules of social conduct that express our shared rationality (Coulter, 1979). The community identifies someone as being mentally ill when they behave unpredictably, for example, or fail to meet basic social expectations like engaging in comprehensible conversation or activity.

Moreover, in some instances the behaviour we refer to as mental illness may not have any discernible meaning or purpose. An episode of extreme over-arousal, such as we might call mania, or less commonly a period of depression, may just occur for no reason, in the same way that not all our daily moods can easily be explained by recent events or circumstances. Hacker highlights how moods and emotions are not instigated by us voluntarily, but nevertheless form part of our character. This is partly because they are intimately connected with our beliefs, opinions and judgements, but also because the way we express our emotions is part of what is characteristic about us as individuals. Yet the behavioural expressions of our emotions are not always fully intentional and sometimes not entirely under our control. Our emotional behaviour can be understood as on a 'spectrum' from the consciously or unconsciously intentional (smiling when greeting a friend) to the involuntary (yawning with boredom). Usually, we are able to exert some degree of control over how we respond to our feelings, and sometimes we might actively resist the feeing itself, when it is anger or jealousy, for example, with more or less success. Yet sometimes we are not able to suppress a smile or a laugh when we know we ought to. Similarly, although not the same situation as an involuntary movement or response (like a spasm), someone in the midst of a serious episode of mental disorder does not seem to be in full control of their behaviour. It seems likely that they are not always able to make reasoned choices about what they do, or to decide to act otherwise.

The issue of agency in relation to mental disorder is highly complex, and Wittgenstein highlights the thin 'line ....between will and ability'. The preceding points suggest that 
regarding mentally disordered behaviour as a part of the self or character, as opposed to an illness or disease that is quite separate from it, does not necessarily entail that the individual should be regarded as fully responsible for all of their actions. Most philosophical commentators believe that in some circumstances, at least, people with mental disorders are not fully autonomous, and therefore cannot be held responsible for certain behaviour (Broome et al, 2010; King \& May, 2018). Generally, in legal situations and ordinary life, we do not hold people responsible if they appear to be unable to make reasoned choices about what they do based on shared principles of rational thought. Szasz, however, argues that psychotic phenomena like delusions and hallucinations, although irrational, may be understood as being purposeful, and, because they emanate from the individual, should be regarded as under their control (Szasz, 1996). Along with other thinkers like Laing and Meyer, therefore, he seems to be suggesting that people may, at times, choose to adopt irrational ways of thinking and behaving. However, although in some places Szasz draws the conclusion that people with mental disorders are 'always responsible for their conduct' (Szasz, 1989) (p. 135), at other points he hints that people may sometimes be considered to be 'incompetent' by virtue of their mental state (Szasz, 1998). He stresses, though, that 'incompetence' is a legal category and should be determined judicially and not medically. Hence, it seems that even Szasz agrees that there are times when agency and responsibility may be compromised in the absence of a physical disease.

Overall, therefore, the constituents of madness or 'mental illness,' are not fundamentally different from other human behaviour and experience, and therefore can be viewed as an aspect of a person's character. What we call mental symptoms arise from the self; often, though not necessarily always, as a reaction to external events, in the same way that more ordinary fears, preoccupations and compulsions arise. In this sense they are expressions of the individual's existence, as R.D. Laing put it (Laing, 1965). The behaviours 
and experiences associated with mental illness are distinctive in a number of ways, however, particularly because they are sometimes not fully rational or controllable. Sometimes 'mentally-ill' behaviour breaks the shared assumptions that enable us to understand and relate to each other; its rationale and motivation are not transparent. Nevertheless, the behaviours we call mental disorder are part of the range of ways in which human beings live within, and interact with, their world.

\section{Implications}

In a world that prizes individual liberty and autonomy, deeming mental disorder to be, or to be like, a disease facilitates certain social mechanisms for addressing the problems it can pose. Szasz argues that the medicalisation of certain challenging behaviours is a strategic manoeuvre that modern societies make in order to justify a system of social control and welfare that would otherwise be highly contentious (Szasz, 1970). David Ingelby, too, shows how presenting certain social arrangements as medical treatments for medical conditions confers a legitimacy they would otherwise lack (Ingelby, 1982). Abandoning the 'medical model' of mental disturbance therefore presents considerable challenges to the legality and acceptability of the modern system of mental health care, and raises questions about how else we might respond to the problems we call mental disorder.

Consider the case of Eric, a fictional patient who presents some of the typical issues encountered in modern services: Eric is a middle-aged man who lives in a block of flats where he is surrounded by other people, including elderly people and families with young children. He periodically shouts throughout the night- he says he is praying- which disturbs his neighbours, and from time to time he thinks they are conspiring against him, and starts threatening them. Taking antipsychotic medication seems to reduce his paranoid thinking and 
makes his behaviour more socially acceptable, but he dislikes it intensely and he does not recognise that there is anything wrong with his behaviour.

If Eric's behaviour is regarded as the manifestation of a brain disease, it does not need to be taken seriously. He is not an eccentric character, who sometimes acts in an anti-social way, but just a walking expression of his brain processes. Therefore it is legitimate to ignore his wishes, and chemically eliminate or suppress the inconvenient behaviour. This is the implicit basis of modern mental health legislation that enables people like Eric to be forcibly confined and medicated on the basis that they have a mental disorder.

If, on the other hand, Eric's behaviour is seen as an expression of his individuality, as an integral part of his character, and not as a disease or sickness, then addressing the situation is complex and more difficult to justify. Outside of the current, mental health system, he could be prosecuted for causing a disturbance to his neighbours, but he would receive a modest penalty and it is unlikely it would make a difference to his behaviour. He could be evicted, but then the same problem would occur elsewhere. Attempts could be made to persuade him to change his behaviour through therapy, but it is difficult to sustain a conversation with him, let alone to conduct therapy. It is probable that he would quickly become homeless and destitute, since he would not qualify for sickness or disability benefits, and his behaviour is incompatible with finding or maintaining employment.

It seems, therefore, that if we reject the notion that mental disorder is a disease, we still need a mechanism that recognises and addresses the difficulties that 'mental disorders' can represent for individuals and others around them. We need a system that can balance the need to restrict people's behaviour when it becomes a nuisance or danger to other people, with the individual's legitimate interests to live in the way they want to live. We also need a 
way to fairly and transparently distribute resources and care to people who are unable to be financially or practically independent, without having to deem them as sick.

Such a system would require a different basis for decisions about depriving someone of their liberty, or forcing them to ingest drugs they do not want to take. Without the justification of treating a medical disease, such decisions would need to involve an explicit process of balancing the interests of different parties, and would have to be subject to greater scrutiny and democratic control than at present. Currently, the notion that mental disorder is a medical condition and that intervention means 'treatment', means there is an inherent bias towards assuming intervention will be helpful and benign. It is also not obvious that the medical profession should have a central role, although medical expertise for the exclusion of physical conditions and safe and rational use of drugs would still be important. There may be pragmatic advantages to locating a new system within the medical system - that is within the existing psychiatric system or something resembling it - such as retaining the prestige and funding that accompanies medical activity. However, the dangers of this would be that proper scrutiny of decisions and balancing of different interests would not be achieved because a medicalised understanding would remain prevalent.

Our current mental health system has extended far beyond the remit of any system of social control, however. Professionals and members of the public alike have welcomed the medicalisation of more familiar forms of distress, such as those we refer to as anxiety and depression. Highlighting again the importance that is attributed to distinguishing disease from behaviour, official information and education about depression emphasises that it is 'a real illness. It is not a sign of a person's weakness or a character flaw' (National Institute of Mental Health, 2018). The idea that depression is a disease, which can be described in biological terms and hence has nothing to do with the individual's real self, is contrasted with the idea that it reflects the person's character and is therefore liable to moral judgement. 
We can appreciate the appeal of embracing the idea that depression is a disease in terms of deflecting blame and responsibility, especially if it is linked with the idea that there is a simple, physical remedy, such as an antidepressant. Yet the separation of the 'depression' from the individual has other consequences that are not necessarily helpful. The depressionas-a-disease approach plays down the role of context or circumstances by locating the problem in the individual's biology, and logically implies that the individual cannot change their situation except by changing their brain. Although all good professionals try and help people to identify and address social and interpersonal issues, people who fully absorb the disease model will realise that it leaves no room for depression to have meaning, and such people wait for antidepressants to 'work', while sometimes enduring circumstances that would make anyone depressed! In this way, the disease concept of depression may trap people in a disabling view that they are fundamentally biologically flawed, with little they can do to help themselves.

If 'depression' is thought of as the emotional response of a whole human being, on the other hand, then it cannot be properly understood without identifying the context or circumstances that it is a response to, and thinking about the nature of the behaviour in which it is manifested. The idea that we can exert some control over our moods, emotions and behaviour encourages people to find ways to change or manage these. . For many, this is fundamental to achieving recovery (Conneely, Higgs, \& Moncrieff, 2019).

\section{Conclusions}

As the above examples illustrate, regarding a situation as a disease or illness has important consequences that flow from the association of these concepts with biological or bodily conditions. Whether mental disorders rightly quality as diseases or whether they should be 
understood as patterns of unwanted behaviour, as suggested by Thomas Szasz, is, therefore, a critical question. Wittgenstein's philosophy illustrates that the 'mental' cannot be equated with the biological, as some philosophers have tried to do, since mental attributes are inherently entwined with public behaviour. In the absence of evidence for a bona fide brain disease, therefore, what we characterise as mental illness or disorder refers to patterns of unusual, but still essentially self-directed behaviour that can, as Wittgenstein suggested, be understood as aspects of character. Such situations have a complex relation to agency, however, because the characteristic experience and behaviours are not always rational or fully controllable.

Due to their implicit association with the body, aligning our understanding of mental disturbance with concepts of disease and illness enables various social functions, including the operation of social control and welfare systems. The idea that mental conditions are a disease is more widely popular because of the exemption from moral judgement that it seems to entail. Accepting the view that madness or mental disorder are varieties of self-directed human behaviour is challenging, but could potentially facilitate more transparent and personally-empowering solutions for the range of problems these situations present.

\section{Acknowledgements:}

I would like to thank Professor Peter Hacker for helpful suggestions on a draft of this paper, Steven Tresker for useful discussion on the philosophy of disease, and to the organising committee of the Association for the Advancement of Philosophy and Psychiatry for giving me the opportunity to collect my thoughts on this subject at the 2017 annual conference. 


\section{References:}

Bennett, M. R., \& Hacker, P. M. S. (2003). The Philosophical Foundations of Neuroscience. Oxford: Wiley-Blackwell.

Boorse, C. (1976). What a theory of mental health should be. Journal for the Theory of Social Behaviour, 6(1), 61-84. doi:10.1111/j.1468-5914.1976.tb00359.x

Broome, M. R., Bortolotti, L., \& Mameli, M. (2010). Moral responsibility and mental illness: a case study. Camb Q Healthc Ethics, 19(2), 179-187. doi:10.1017/S0963180109990442

Canguilhem, G. (2012). Writings on Medicine (Forms of Living). New York: Fordham University Press.

Churchland, P. (2006). The big questions: . New Scientist, 2578(18th Nov), 42-45.

Conneely, M., Higgs, P., \& Moncrieff, J. (2019). Medicalising the moral: the case of depression as revealed in internet blogs. Soical Theory and Health, submitted.

Coulter, J. (1979). The Social Construction of Mind. London: Macmillan.

Craddock, N., Antebi, D., Attenburrow, M. J., Bailey, A., Carson, A., Cowen, P., . . Zammit, S. (2008). Wake-up call for British psychiatry. Br.J.Psychiatry, 193(1), 6-9.

Fulford, K. W. M. (1989). Moral theory and medical practice. Cambridge: Cambridge University Press.

Hacker, P. M. (2004). The conceptual framework for the investigation of emotions. Int Rev Psychiatry, 16(3), 199-208. doi:10.1080/09540260400003883

Hacker, P. M. S. (1997). Wittgenstein. London: Phoenix.

Hacker, P. M. S. (2010). Human Nature: The Categorical Framework. Oxford: Wiley-Blackwell.

Hartner, D. F., \& Theurer, K. L. (2018). Psychiatry should not seek mechanisms of disorder. Journal of Theoretical and Philosophical Psychology, 38(4), 189-204. doi:10.1037/teo0000095

Healy, D. (2015). Serotonin and depression. BMJ, 350, h1771. doi:10.1136/bmj.h1771

Ingelby, D. (1982). The Social Construction of Mental Illness. In P. Wright \& A. Treacher (Eds.), The Problem of Medical Knowledge (pp. 123-143). Edinburgh: Edinburgh University Press. (Reprinted from: NOT IN FILE).

Insel, T. R., \& Cuthbert, B. N. (2015). Medicine. Brain disorders? Precisely. Science, 348(6234), 499500. doi:10.1126/science.aab2358

Kendler, K. S., \& Schaffner, K. F. (2011). The dopamine hypothesis of schizophrenia: an historical and philosophical analysis. Philosophy, Psychiatry \& Psychology, 18(1), 41-63.

Kendler, K. S., Zachar, P., \& Craver, C. (2011). What kinds of things are psychiatric disorders? Psychol Med, 41(6), 1143-1150. doi:10.1017/S0033291710001844

King, M., \& May, J. (2018). Moral responsibility and mental ilnness: a call for nuance. Neuroethics, 11(1), 11-22.

Laing, R. D. (1965). The Divided Self. Pelican Books.

Meyer, A. (1948). The commonsense psychiatry of Dr Adolf Meyer. New York: McGraw Hill.

Moncrieff, J. (2009). A critique of the dopamine hypothesis of schizophrenia and psychosis. Harv. Rev. Psychiatry, 17(3), 214-225.

Moncrieff, J., \& Middleton, H. (2015). Schizophrenia: a critical psychiatry per spective. Curr.Opin. Psychiatry, 28(3), 264-268.

Nachev, P., \& Hacker, P. (2014). The neural antecedents to voluntary action: a conceptual analysis. Cogn Neurosci, 5(3-4), 193-208. doi:10.1080/17588928.2014.934215

National Institute of Mental Health. (2018). Depression: what you need to know. Retrieved from https://www.nimh.nih.gov/health/publications/depression-what-you-need-toknow/index.shtml

Sedgwick, P. (1982). Psycho politics. London: Pluto Press.

Szasz, T. (1970). Ideology and Insanity; essays on the psychiatric dehumanization of man. New York: Anchor Books.

Szasz, T. (1989). Law, Liberty and Psychiatry: an inquiry into the social uses of mental health. Syracuse, New York: Syracuse University Press.

Szasz, T. (1990). The Untamed Tongue. Chicago: Open Court. 
Szasz, T. (1996). The meaning of mind: language, morality and neuroscience. Westport, CT: Praeger.

Szasz, T. (1998). Thomas Szasz' summary statement and manifesto. Retrieved from https://www.szasz.com/manifesto.html

Szasz, T. (2000). Mental disorders are not diseases. Retrieved from http://www.szasz.com/usatoday.html

Tallis, R. (2011). Aping Mankind: Neuromania, Darwinitis and the Misrepresentation of Humanity. London: Acumen Publishing.

Wakefield, J. C. (1992). Disorder as harmful dysfunction: a conceptual critique of DSM-III-R's definition of mental disorder. Psychol.Rev., 99(2), 232-247.

Winch, P. (2008). The Idea of a Social Science and its Relation to Philosophy (Vol. Routledge Classics edition). London: Routledge.

Wittgenstein, L. (1953). Philosophical Investigations. Oxford: Basil Blackwell.

Wittgenstein, L. (1970). Culture and Value. Oxford: Basil Blackwell.

Zachar, P. (2002). The Practical Kinds Model as a Pragmatist Theory of Classification: Comment. Philosophy, Psychiatry, \& Psychology, 9(3). doi:10.1353/ppp.2003.0051

\footnotetext{
' Positivism is the movement that proposed that the methods of the natural sciences could be applied to the study of human behaviour and society.

ii Philosophical critiques of neurodeterminism highlight how thoughts and actions derive their meaning from their place within the complex whole constituted by human language and social behaviour. Their significance can never be captured by descriptions in terms of neurological events, even if these did accurately map onto specific thoughts and actions, which seems unlikely (Bennett \& Hacker, 2003; Nachev \& Hacker, 2014; Tallis, 2011).
} 